\title{
Free will in the brain?
}

\author{
Neil Levy ${ }^{1,2}$ (ID
}

Received: 17 December 2020 / Accepted: 31 January 2021 / Published online: 6 February 2021

(C) The Author(s), under exclusive licence to Springer-Verlag GmbH, AT part of Springer Nature 2021

\begin{abstract}
In this brief commentary on Rickard L Sjöberg's "Free will and neurosurgical resections of the supplementary motor area," I argue that his interpretation of the data on the role of the SMA in voluntary movement, and his conclusion that such data does not resolve the free will debate, is consistent with what we should expect from a philosophical point of view. The hope that this data could resolve the question of free will depends on a view of free will as a magical power, and we have no reason to believe in the existence of magic.
\end{abstract}

Keywords Free will $\cdot$ Supplementary motor area $\cdot$ Rickard L Sjöberg

Free will, if it exists, must have its locus in decision-making, and decisions are mental events. Mental events, in turn, depend in some way on events and processes in the brain. Perhaps they just are brain events. As our capacity to probe the brain improved across the last half century, it was inevitable that we would apply them to attempts at understanding, vindicating or debunking free will.

A major focus has been on Benjamin Libet's finding that our awareness of our having settled on a decision was preceded by a surge of activity in the supplementary motor area $[5$, 6]. Many commentators took this finding to debunk free will $[7,9,11]$. Libet's data allegedly show that conscious awareness does not initiate our voluntary movements, and such initiation is (again, allegedly) essential to the possession of free will.

In that light, Rickard L Sjöberg's [8] conclusion that in the end, the convergent evidence on the role of the SMA in voluntary movement does not allow us to resolve questions about free will will be disappointing to many. On Sjöberg's model, SMA is a gateway to voluntary movement, not its ultimate source. While the SMA is the proximal cause of voluntary decision and movement, the data are consistent with its

Neil Levy

neil.levy@philosophy.ox.ac.uk

1 Department of Philosophy, Macquarie University, Sydney, NSW 2109, Australia

2 Uehiro Centre for Practical Ethics, University of Oxford, Oxford OX1 1PT, UK integrating goals and choices rather than being their ultimate cause.

Sjöberg's contribution is a valuable one in increasing our understanding of the role of the SMA in voluntary movement, whether it advances the free will debate or not. In fact, his conclusion that these data cannot resolve the free will debate is exactly what we should expect. Those who thought free will depends on prior conscious initiation of action were asking for evidence of magic, and we should not expect neuroscience to show us magic.

Human beings are a kind of animal who live in a physical universe. Our mental events are, or are dependent on, physical events. We should expect the event that consists in a decision to have causes that precede it. If it turns out to be a conscious event, its causes will not be conscious. Our decisions are likely the product of long chains of causes, perhaps chains that date back to before we were born.

It is certainly possible - consistent with our physics and our neuroscience - that the event that consists in our deciding is uncaused. But it is difficult to see how uncaused events or uncaused causes would make us free. Free decisions, if they exist, are made for reasons, and those reasons must be among its causes. We are not free if our decisions are uncaused, conscious or not. In that case, we respond randomly, and a random decision is not one in virtue of which we are responsible, for which we should be proud or ashamed.

Some philosophers, and implicitly those neuroscientists who have suggested that free will depends on a conscious decision that is somehow intrinsically free - a free decision that is not caused by prior events, and therefore not caused by our reasons-have asked for magic [4]. The idea of an 
intrinsically free decision, an uncaused cause that is not merely arbitrary, makes little conceptual sense. Those who took Libet's data to refute the existence of free will demanded something impossible: they asked for evidence of magic, and then concluded that free will did not exist because (unsurprisingly) no such evidence could be produced.

The traditional philosophical debate over the existence of free will has focused on whether our actions are causally determined. Some philosophers think that if our decisions are determined - if how we decided was already in some sense settled long before we decided - then we are not free $[3,10]$. Compatibilists, who hold that freedom is compatible with causal determinism, emphasise that what matters is that the causes are good ones: genuine reasons $[1,2]$. The data from neuroscience is consistent with both models. Perhaps our decisions are deterministically caused by our reasonsour goals, our values, our perception of our current optionswith the SMA integrating these sometimes conflicting causes. Perhaps instead the causal chain is indeterministic, as some interpretations of quantum mechanics suggest. The data so far is neutral between these models.

Sjöberg's contribution leaves the issue of free will unresolved, but it contributes to a better understanding of ourselves. Neuroscience may not resolve the question of whether we have free will, but self-understanding, too, is a traditional goal of philosophy. Philosophy will not be replaced by neuroscience anytime soon, but work like this shows how it cannot neglect science either. There is no magic in the brain or the world, but the awesome universe revealed by science is a more satisfying replacement.

\section{References}

1. Dennett D (2003) Freedom evolves. Allen Lane, London

2. Fischer JM, Ravizza M (1998) Responsibility and control: a theory of moral responsibility. Cambridge University Press, Cambridge

3. Kane R (1996) The significance of free will. Oxford University Press, New York

4. Levy N (2005) Libet's impossible demand. J Conscious Stud 12: $67-76$

5. Libet B (1999) Do we have free will? In: Libet B, Freeman A, Sutherland K (eds) The volitional brain: toward a neuroscience of free will. Imprint Academic, Thorverton, pp 47-57

6. Libet B, Gleason CA, Wright EW, Pearl DK (1983) Time of conscious intention to act in relation to onset of cerebral activity (readiness-potential): The unconscious initiation of a freely voluntary act. Brain 106:623-642

7. Pockett S (2004) Does consciousness cause behaviour? J Conscious Stud 11:23-40

8. Sjöberg RL (In press) Free will and neurosurgical resections of the supplementary motor area: a critical review. Acta Neurochir

9. Spence A (1996) Free will in the light of neuropsychiatry. Philos Psychiatry Psychol 3:75-90

10. Van Inwagen P (1983) An essay on free will. Oxford University Press, Oxford

11. Wegner DM (2002) The illusion of conscious will. MIT Press, Cambridge

Publisher's note Springer Nature remains neutral with regard to jurisdictional claims in published maps and institutional affiliations. 